\title{
Magma mixing enhanced by bubble segregation
}

\author{
S. Wiesmaier ${ }^{1,2}$, D. Morgavi ${ }^{1,3}$, C. J. Renggli ${ }^{4}$, D. Perugini ${ }^{3}$, C. P. De Campos $^{1}$, K.-U. Hess ${ }^{1}$, W. Ertel-Ingrisch ${ }^{1}$, \\ Y. Lavallée ${ }^{5}$, and D. B. Dingwell ${ }^{1}$ \\ ${ }^{1}$ Dept. of Earth and Environmental Sciences, Ludwig-Maximilians-Universität München, 80333 Münich, Germany \\ ${ }^{2}$ GEOVOL, Universidad de Las Palmas de Gran Canaria, 35017 Las Palmas de Gran Canaria, Spain \\ ${ }^{3}$ Department of Physics and Geology, University of Perugia, 06100 Perugia, Italy \\ ${ }^{4}$ Research School of Earth Sciences, Australian National University, Canberra ACT 0200, Australia \\ ${ }^{5}$ Earth, Ocean and Ecological Sciences, University of Liverpool, Liverpool, L69 3GP, UK
}

Correspondence to: S. Wiesmaier (sebastian.wiesmaier@min.uni-muenchen.de)

Received: 22 March 2015 - Published in Solid Earth Discuss.: 22 April 2015

Revised: 8 July 2015 - Accepted: 1 August 2015 - Published: 21 August 2015

\begin{abstract}
In order to explore the materials' complexity induced by bubbles rising through mixing magmas, bubbleadvection experiments have been performed, employing natural silicate melts at magmatic temperatures. A cylinder of basaltic glass was placed below a cylinder of rhyolitic glass. Upon melting, bubbles formed from interstitial air. During the course of the experimental runs, those bubbles rose via buoyancy forces into the rhyolitic melt, thereby entraining tails of basaltic liquid. In the experimental run products, these plume-like filaments of advected basalt within rhyolite were clearly visible and were characterised by microCT and high-resolution EMP analyses.

The entrained filaments of mafic material have been hybridised. Their post-experimental compositions range from the originally basaltic composition through andesitic to rhyolitic composition. Rheological modelling of the compositions of these hybridised filaments yield viscosities up to 2 orders of magnitude lower than that of the host rhyolitic liquid. Importantly, such lowered viscosities inside the filaments implies that rising bubbles can ascend more efficiently through pre-existing filaments that have been generated by earlier ascending bubbles. MicroCT imaging of the run products provides textural confirmation of the phenomenon of bubbles trailing one another through filaments. This phenomenon enhances the relevance of bubble advection in magma mixing scenarios, implying as it does so, an acceleration of bubble ascent due to the decreased viscous resistance facing bubbles inside filaments and yielding enhanced mass flux of mafic melt into felsic melt via entrainment. In magma mixing events involving melts of high
\end{abstract}

volatile content, bubbles may be an essential catalyst for magma mixing.

Moreover, the reduced viscosity contrast within filaments implies repeated replenishment of filaments with fresh endmember melt. As a result, complex compositional gradients and therefore diffusion systematics can be expected at the filament-host melt interface, due to the repetitive nature of the process. However, previously magmatic filaments were tacitly assumed to be of single-pulse origin. Consequently, the potential for multi-pulse filaments has to be considered in outcrop analyses. As compositional profiles alone may remain ambiguous for constraining the origin of filaments, and as 3-D visual evidence demonstrates that filaments may have experienced multiple bubbles passages even when featuring standard diffusion gradients, therefore, the calculation of diffusive timescales may be inadequate for constraining timescales in cases where bubbles have played an essential role in magma mixing. Data analysis employing concentration variance relaxation in natural samples can distinguish conventional single-pulse filaments from advection via multiple bubble ascent advection in natural samples, raising the prospect of yet another powerful application of this novel petrological tool.

\section{Introduction}

Bubbles rising across fluid-fluid interfaces between two fluids may entrain and transport portions of one fluid into the other (e.g. Thomas et al., 1993; Manga and Stone, 1995). As 
scenarios involving two fluids are the core feature of magma mixing, we have tested here whether bubble ascent may be capable of catalysing the intermingling of two silicate melts and thus contribute to efficient advective mingling of two distinct magmas.

Past experiments with analogue materials have clearly demonstrated the potential for rising gas bubbles to drag portions of one liquid into another (Thomas et al., 1993). Both single bubbles and clusters of bubbles (as two-phase plumes) were observed to help to propel portions of liquid of lower viscosity into an overlying liquid of higher viscosity. Manga and Stone (1995) laid the fluid dynamical foundation of this problem by analysing the low Reynolds number motion of bubbles or drops (generally: particles) that pass through fluid-fluid interfaces. Among other scenarios that the study dealt with was a single bubble rising from low-viscosity to high-viscosity fluid, thereby entraining parts of low-viscosity fluid into the upper high-viscosity one. Numerical constraints from that study indicate the importance of the viscosity contrasts between (a) fluid and gas and (b) fluid and fluid. The analogue studies of Thomas et al. (1993) and Manga and Stone (1995) argue strongly in favour of bubble-driven mixing scenarios. Nevertheless, experiments with analogue liquids are incapable of exploring the diffusive equilibration of the multi-component silicate melts which participate in magma mixing events in nature.

Here, we demonstrate the mechanism of bubble advection, using natural melts at magmatic temperatures. As mafic or hybrid filaments found in natural samples of igneous rocks are typically interpreted to be a result of convection-driven stretching and folding scenarios, we present below a solution to distinguish such conventional filaments from filaments formed by bubbles.

\section{Background}

\subsection{Chaotic mixing}

Over the last 2 decades, magma mixing has received renewed attention in petrology (Wilcox, 1999). Traditionally, magma mixing has served as an explanation wherever a suite of igneous rocks has yielded straight-line trends in chemical variation diagrams of major elements (e.g. Wiesmaier et al., 2012). Recently, however, magma mixing has been recognised to produce non-linear mixing trends on a micro-scale due to diffusive fractionation of elements (Perugini and Poli, 2000, 2004; Perugini et al., 2003; De Campos et al., 2010). Straight trends in entire sample suites, in turn, are most likely the result of performing sample analyses in bulk. As in natural magma mixing scenarios, the diffusive fraction of elements is always combined with variable degrees of irreversible and chaotic fluid mechanic interaction (mingling); the term chaotic mixing was coined (Perugini and Poli, 2000; Perugini et al., 2012). Chaotic mixing fundamentally decon- structs magma mixing in these two realms and shows that both separate phenomena (mingling and diffusion) are necessary to achieve efficient hybridisation.

This dual nature of chaotic mixing allows us to investigate how mingling processes pre-determine the efficacy of magma mixing. Mingling may stretch and fold each liquid member, depending on its rheological properties, and thus results in increasingly complex 3-D morphologies in the form of filaments and blobs (see Perugini et al., 2002). Because of the chaotic nature of mingling, de-mingling is precluded and physical mingling is irreversible. This irreversibility is enhanced by diffusion, which starts immediately in the presence of a compositional gradient at magmatic temperatures and smears the boundaries between two fluids. Without diffusion, mingling would be able to generate infinitesimally small, chemically discrete filaments of two intertwined magmas. Because, however, diffusion is initiated at the moment of juxtaposition of the two magmas, infinitesimal filaments do not occur. During magma mingling, diffusion drives a two-fluid system towards chemical homogenisation. This diffusion may or may not run to completion. Its efficacy is highly dependent on the surface/volume ratio of the involved liquids, where high surface/volume ratios of the liquids (or complex 3-D morphologies) exponentially decrease the diffusive length scales (Perugini et al., 2003; De Campos et al., 2011). Because mingling generally increases the surface / volume ratio of the involved magmas, it follows that the efficacy of different mingling mechanisms affects the overall efficacy of magma mixing.

\subsection{Mechanisms of stirring or mingling magma}

Magmas are mingled in nature through manifold mechanisms, which are fundamentally buoyancy-related. In detail, however, each of the mechanisms has its own dynamics. For example, during (i) conduit flow, the interface of two separate magmas may become instable and produce "streaky mixtures" of the two members. Although buoyancy-driven, conduit flow mixing is related to turbulence in the conduit, which may form at a lower $R e$ number than expected for turbulence in isoviscous flow (Blake and Campbell, 1986). (ii) Vigorous convection in a magma reservoir, in turn, forms through strong $T$ contrasts from transient mafic replenishment and may entrain, stretch, and fold portions of mafic magma by viscous coupling (Huppert et al., 1983, 1984; Snyder and Tait, 1996). (iii) Double-diffusive convection depends on thermal and chemical diffusivities, resulting when "these two components make opposing contributions to the vertical density gradient" in a magma reservoir (Huppert and Turner, 1981). The implications of double-diffusive convection range from small-scale percolation of more felsic melts along the sidewall of a reservoir, to catastrophic overturn when a replenishing mafic magma fractionates and becomes less dense than an overlying layer of magma. (iv) Forced intrusion implies a competent, felsic body of magma (mush), 
Table 1. Composition of end-member glasses from the Snake River Plain (data from Morgavi et al., 2013a).

\begin{tabular}{lcc}
\hline [wt\%] & SRP Basalt & SRP Rhyolite \\
\hline $\mathrm{SiO}_{2}$ & 48.11 & 79.16 \\
$\mathrm{Al}_{2} \mathrm{O}_{3}$ & 16.19 & 9.81 \\
$\mathrm{TiO}_{2}$ & 1.76 & 0.23 \\
$\mathrm{MgO}$ & 7.42 & 0.12 \\
$\mathrm{FeO}$ tot & 12.12 & 1.84 \\
$\mathrm{MnO}$ & 0.28 & 0 \\
$\mathrm{CaO}$ & 11.46 & 0.83 \\
$\mathrm{Na} 2 \mathrm{O}$ & 1.94 & 3.47 \\
$\mathrm{~K}_{2} \mathrm{O}$ & 0.31 & 4.53 \\
$\mathrm{P}_{2} \mathrm{O}_{5}$ & 0.43 & 0 \\
\hline Total & 100 & 100 \\
\hline
\end{tabular}

almost solidified but still hot, which is being intruded by a mafic dyke (Pallister et al., 1992; Izbekov et al., 2004). Simultaneous reheating of the felsic magma may lead to collapse of the dyke, because the surrounding felsic magma melts and loses strength to contain the magma in a rigid conduit. In such cases, highly variable quench textures in mafic enclaves may record the diminishing temperature contrast between mafic and felsic members (Wiesmaier et al., 2011).

The role of bubbles in magma mixing has so far been limited to their density-reducing effect on magma-bubble suspensions. Rapid exsolution of volatiles may reduce the bulk density of layers of basaltic magma to become less dense than an overlying layer of felsic magma (e.g. Tait and Jaupart, 1989; Ruprecht et al., 2008). The resulting instable configuration may then lead to a catastrophic overturn and eruption of an entire magma reservoir (e.g. Woods and Cowan, 2009). In chemical engineering, however, bubble mixing is a long-recognised concept. Devices and setups exploiting the buoyancy force of gas in liquids have been employed for example in medical and biochemical applications (e.g. Sánchez Mirón et al., 2004), fining of glass melts, waste water treatment plants and blending of wines and spirits.

\section{Methodology}

\subsection{Glass preparation}

The experiment has been carried out with two natural endmember compositions, basalt and rhyolite. Sample material was obtained in the form of blocks $(>30 \mathrm{~cm})$ from the Bruneau-Jarbidge eruptive centre of the Snake River PlainYellowstone hotspot track. The rhyolite sample is from Unit $\mathrm{V}$ of the Cougar Point Tuff and the basalt sample from Mary's Creek (see Bonnichsen, 1982; Cathey and Nash, 2009). Samples of these units have been used in previous studies (see Morgavi et al., 2013a, b, c). The basalt is of
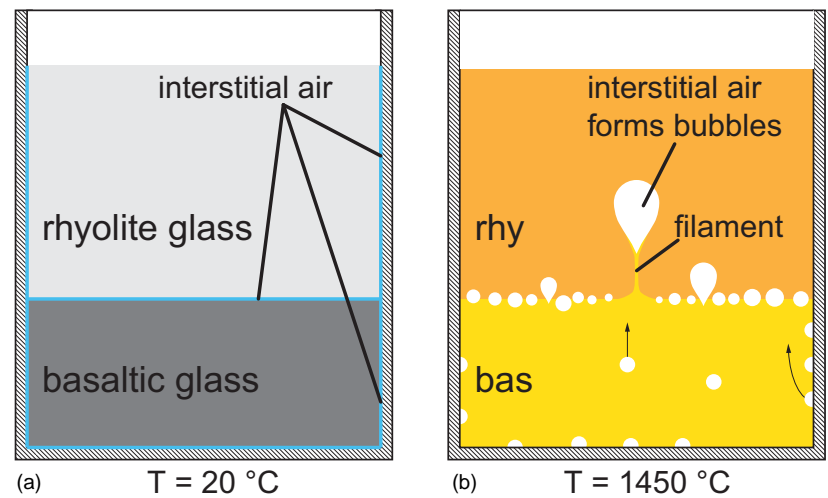

Figure 1. Experimental setup. (a) Glass cylinders of basalt and rhyolite were placed above each other at room $T$ into a Pt-crucible and heated to $1450^{\circ} \mathrm{C}$. (b) Air trapped in-between the glass cylinders expands and forms bubbles upon heating.

tholeiitic composition, and the rhyolite belongs to the subalkaline series (Table 1).

Both materials were freed from weathered surfaces and crushed. After milling in a laboratory disc mill, the basalt and rhyolite powders were melted and homogenised in a concentric cylinder viscometer (Dingwell, 1986) at 6 and $24 \mathrm{~h}$ respectively to ensure that the materials were exempt of crystals and gas bubbles. Both basalt and rhyolite melts were quenched in air at room temperature. The glasses were cored from the crucibles and machined to cylinders that fit into a Pt-crucible of $25 \mathrm{~mm}$ diameter.

\subsection{Experimental setup}

At room temperature, a cylinder of Snake River Plain (SRP) rhyolite glass was placed above a cylinder of SRP basaltic glass in a Pt-crucible of $25 \mathrm{~mm}$ inner diameter (Fig. 1). This experimental charge was placed into a furnace at $1450^{\circ} \mathrm{C}$ to remelt both glass cylinders. The heating rate was on the order of $5-15 \mathrm{~K} \mathrm{~s}^{-1}$ based on thermal diffusivity calculations. The target temperature was chosen to (a) keep the melts at superliquidus temperatures to avoid complexities associated with crystals and (b) to achieve an appropriate viscosity for the rhyolite. Prior to the experiment, viscosity of the melts was measured by rotational viscometry and, at $1450^{\circ} \mathrm{C}$, found to be ca. $10^{0.4} \mathrm{~Pa} \mathrm{~s}^{-1}$ for the SRP basaltic melt and ca. $10^{4} \mathrm{~Pa} \mathrm{~s}^{-1}$ for the SRP rhyolitic melt (Morgavi et al., 2013a). As such, the relatively lower viscosity of our experimental rhyolite melt compared to that of a natural, $\mathrm{H}_{2} \mathrm{O}$-bearing rhyolite magma at depth, ensures reasonable experimental run times, while maintaining fluid mechanical scalability.

Upon heating and melting, air trapped in the interstices between the glass cylinders and crucible walls contributed to the formation of bubbles. Thin spaces of air were present underneath the basalt, between basalt and rhyolite, and between the crucible wall and both glass cylinders. Bubbles were thus able to form below the melts as well as at the side- 
walls, which ensured unconstrained rising paths of bubbles. According to the ideal gas law, the increase in volume of the trapped air from $293 \mathrm{~K}\left(20^{\circ} \mathrm{C}\right)$ to $1723 \mathrm{~K}\left(1450^{\circ} \mathrm{C}\right)$ was ca. 6-fold. Oxygen fugacity was held constant in equilibrium with air at 1 bar.

The bubbles ascended into the rhyolite entraining basaltic melt to create vertical filaments (see Manga and Stone, 1995). Stokes' Law calculations indicated ca. $240 \mathrm{~min}$ for a bubble of radius $2 \mathrm{~mm}$ to rise through the rhyolite. At $t=180 \mathrm{~min}$, the crucible was removed from the furnace and cooled in air to room temperature. The quench rate is estimated to range around few degrees per second, similar to studies using comparable procedures (e.g. Chevrel et al., 2015). The post-experimental glassy assemblage was cored from the crucible to yield a sample cylinder of $20 \mathrm{~mm}$ diameter. This run product was characterised by microCT and subsequent high-resolution EMP analyses.

\subsubsection{Fluid dynamic parameters}

We have employed dimensionless numbers within the framework of Manga and Stone (1995) to constrain the experiment in fluid dynamic terms. The dimensionless Reynolds number $R e$ is the ratio of inertial to viscous forces and describes the flow regime of a fluid dynamical problem. For a sphere in a fluid, the characteristic length scale $L$ is the radius of the sphere (here: bubble), the velocity $v$ is Stokes' terminal settling velocity, and $\rho$ and $\mu$ are density and viscosity of the fluid.

$$
R e=\frac{\rho v L}{\mu}
$$

The dimensionless Bond number $B o$, also called Eötvös number, is used in combination with the Morton number $M o$ to describe the shape of a bubble or drop in a fluid. The $B o$ number is defined as the ratio of the body forces to the surface tension affecting the bubble, with $\Delta \rho$ the density difference between fluid and bubble, $g$ the gravitational acceleration, $L$ the radius of the bubble and $\sigma$ the surface tension of the fluid.

$B o=\frac{\Delta \rho g L^{2}}{\sigma}$

The current experiment is closely related to the numerical and analogue experimental approach of Manga and Stone (1995). Our system of rhyolitic and basaltic fluids and a free gas phase (air) is characterised following their nomenclature; (i) the ratio of drop (bubble) to lower fluid viscosity $\lambda$ ranges around $2.35 \times 10^{-5}$, (ii) the ratio of upper to lower fluid viscosity $\gamma$ is ca. $4 \times 10^{3}$, and (iii) a buoyancy parameter $\beta$, which approximates the buoyancy difference of the bubble translating from one liquid to another, is approximately 0.79 ; that is, the bubble in the rhyolite experiences $79 \%$ of the buoyancy it had in the basalt. The Re number for a bubble of $4 \mathrm{~mm}$ radius rising through rhyolite ranges on the order of
$1 \times 10^{-9}$. Bond numbers are $B o_{\text {bas }}=0.38$ for the bubble in basalt, and $B o_{\text {rhy }}=0.30$ for the bubble in rhyolite, using surface tension values for dry silicate melts from Bagdassarov et al. (2000). The Bond number for the interface of basaltic and rhyolitic melt is assumed to be $\infty$ for the transient nature of surface tension between miscible liquids (cf. Mungall, 1994; Lacaze et al., 2010 and references therein). The present study extends the array of relevant fluid mechanical problems to low $R e$, low $B o$ and high log-Morton numbers (cf. Clift et al., 2005, Fig. 2.5 therein).

\subsection{Micro Computed Tomography (MicroCT) analysis}

MicroCT provided a non-destructive means to characterise the experimental products both qualitatively and quantitatively. MicroCT scanning was performed at IMETUM, Garching, Germany using a General Electric v|tome $\mid x s^{\odot}$ device equipped with a microfocal x-ray tube. Altogether 1000 scans were carried out at $80 \mathrm{kV}, 250 \mu \mathrm{A}$ at an exposure time of $333 \mathrm{~ms}$ per scan. Each scan was conducted as the average of three individual scans for noise reduction. The beam was moderated by a $0 \mathrm{p} 3 \mathrm{va}$ filter for reduced beam hardening. An effective voxel size of $50 \mu \mathrm{m}$ was achieved. Subsequent reconstruction was conducted with VGStudio MAX ${ }^{\odot}$. The resulting stack of tiff files was then converted to a volume file (.vox) using writeVOX, an auxiliary program of our custommade, MATLAB-based Tomoview software package. The vox file was segmented in Tomoview and quantified for size parameters of subspherical bubbles.

\subsection{Electron microprobe (EMP) analysis}

Discs of experimental glass were prepared as electron microprobe mounts. One or several filaments per microprobe mount were analysed for major element concentrations using a Cameca SX100 electron microprobe at LMU Munich. Measurements were carried out at $15 \mathrm{kV}$ acceleration voltage and $20 \mathrm{nA}$ beam current. To counter alkali loss, Scherrer (2012) found a defocused $10 \mu \mathrm{m}$ beam as the best solution for that instrument. Standards used were: synthetic wollastonite $(\mathrm{Ca}, \mathrm{Si})$, periclase $(\mathrm{Mg})$, hematite $(\mathrm{Fe})$, corundum $(\mathrm{Al})$, natural orthoclase $(\mathrm{K})$, and albite $(\mathrm{Na})$. Matrix correction was performed by PAP procedure (Pouchou and Pichoir, 1984). The precision was below $2.5 \%$ for all analysed elements. Accuracy was tested by analysing MPI-DING standard glasses (e.g. Jochum et al., 2000) and is better than $3.0 \%$ for the analysed elements.

\subsection{Filament thickness}

The thickness of experimental filaments has been determined for subsequent statistical analysis. In the final experimental charge, the original filament thickness is not preserved, because the onset of diffusion "smears out" the borders of filaments. Therefore, the thickness of filaments has arbitrarily been defined as the distance between the inflection points in 

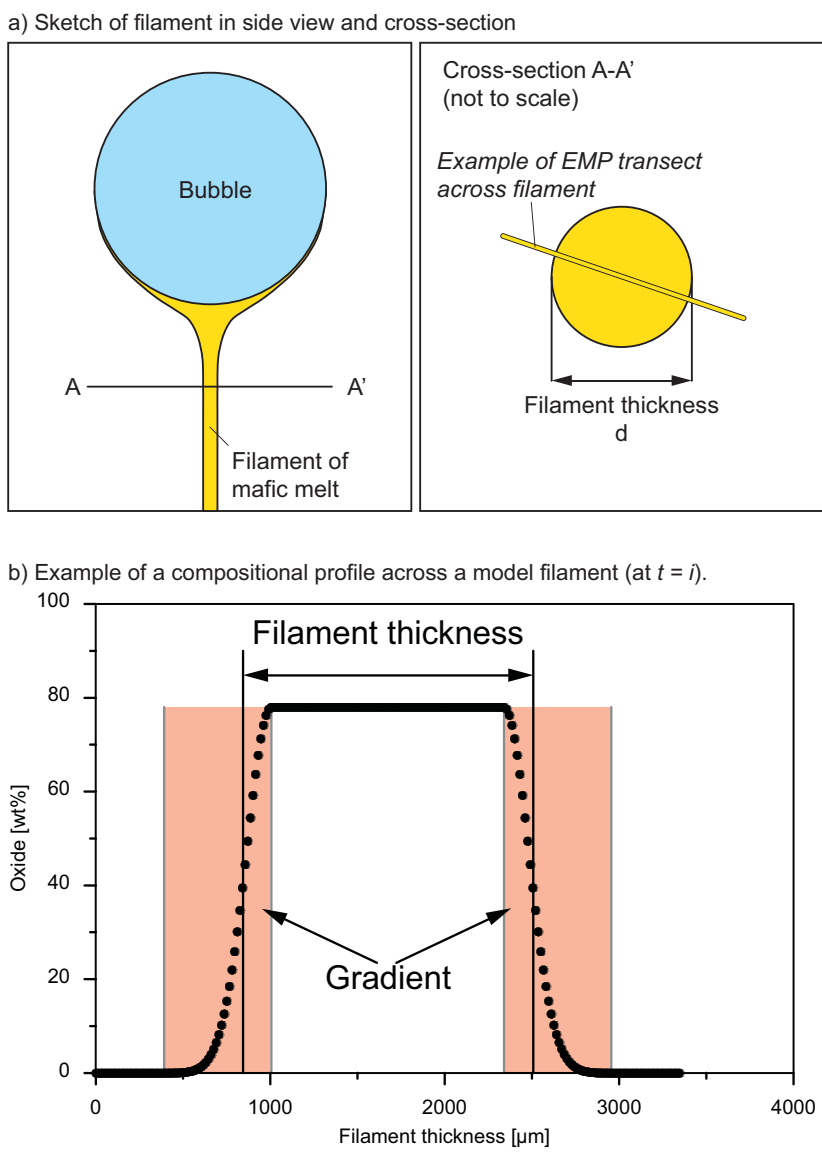

Figure 2. (a) Sketch of filament formation by bubble ascent in side view and cross section. Mafic melt (yellow) is attached to bubble and dragged upwards by the buoyancy of the bubble. The surrounding liquid is not shaded for clarity. The column-like filament appears circular-shaped in cross section $\mathrm{A}-\mathrm{A}^{\prime}$. EMP transects have been performed over comparable cross sections of the experimental run products. (b) Modelled compositional profile at $t=i$. Filament thickness is determined by selecting the inflection points of each profile. Red-shaded areas mark the calculated gradient, whereas flat parts have been arbitrarily added to vary filament thickness. The modelled profiles are then used for calculation of concentration variance $\sigma^{2}$ in an ideal case and subsequently compared to $\sigma^{2}$ values of actually measured compositional profiles of the run products.

the $\mathrm{SiO}_{2}$ vs. distance curves (Fig. 2). As the main component of silicate melts, $\mathrm{Si}^{4+}$ represents a robust and reproducible proxy for filament thickness, not least for its relatively sluggish diffusion (Dingwell, 1990). According to this procedure, filament thicknesses of the nine EMP transects analysed here range from ca. 70 through to $1650 \mu \mathrm{m}$. Potential errors from variable diffusivities of a single species in multi-component silicate melts are deemed insignificant due to the short run time of $180 \mathrm{~min}$ and the slow diffusivity of silica.

\subsection{Calculation of concentration variance}

Concentration variance $\sigma^{2}$ represents a statistical measure for the degree of homogenisation of a filament and has been applied successfully in previous experimental studies on magma mixing (Morgavi et al., 2012, 2013a, b, c; Perugini et al., 2013). The calculation of $\sigma^{2}$ is given by

$\sigma^{2}=\frac{\sum_{i=1}^{N}\left(C_{i}-\mu_{i}\right)^{2}}{N}$,

where $N$ is the number of samples, $C_{i}$ is the concentration of element $i$, and $\mu$ is the mean composition. In order to provide readable numbers, we normalise concentration variance at time $t$ to the initial variance at $t=0$ :

$\sigma_{n}^{2}=\frac{\sigma^{2}\left(C_{i}\right)_{t}}{\sigma^{2}\left(C_{i}\right)_{t=0}}$

As a result, a value of 0 for $\sigma^{2}$ represents complete homogenisation, whereas a value of 1 equals completely separate end-members.

We calculated $\sigma^{2}$ for all EMP transects measured on the experimental run product. The length of the overall transect was set to double the filament thickness (see Sect. 3.5). For transects longer than double the filament thickness, data points were excluded from the calculation of $\sigma^{2}$. For transects shorter than double the filament thickness, artificial data points of rhyolite end-member composition have been appended at the end of these transects. This ensured a correct statistical comparability of $\sigma^{2}$ of different transects. Notably, this procedure has only been used for the calculation of concentration variance, and all compositional data presented are as measured from EMP analysis.

\subsection{Model filaments}

Model filaments were calculated to demonstrate the correlation of concentration variance with filament thickness in an ideal case. These ideal diffusion gradients have been modelled based on the thin-source problem, using the following equation:

$C(x, t)=C_{0} e^{-x^{2} /(4 D t)}$,

where $x$ is the distance measured from the interface between end-members, $C$ is the concentration of the diffusant, $C_{0}$ is the concentration of the diffusant at the interface $(x=0), D$ is the diffusivity, and $t$ is time (after Eq. 37 in Zhang, 2010). The diffusivity $\mathrm{D}$ is kept constant in the calculation and has been arbitrarily set to $1 \times 10^{-11} \mathrm{~m}^{2} \mathrm{~s}^{-1}$. For $\mathrm{C}_{0}$, a value of $78 \mathrm{wt} \%$ has been used. For each model filament, $C$ was calculated every $15 \mu \mathrm{m}$, comparable to the step length of the analytical profiles obtained by EMP in this study. The resulting gradient of compositional variation was used as the 


\section{D view of run product: $\quad$ BSE images of cross-sections:}

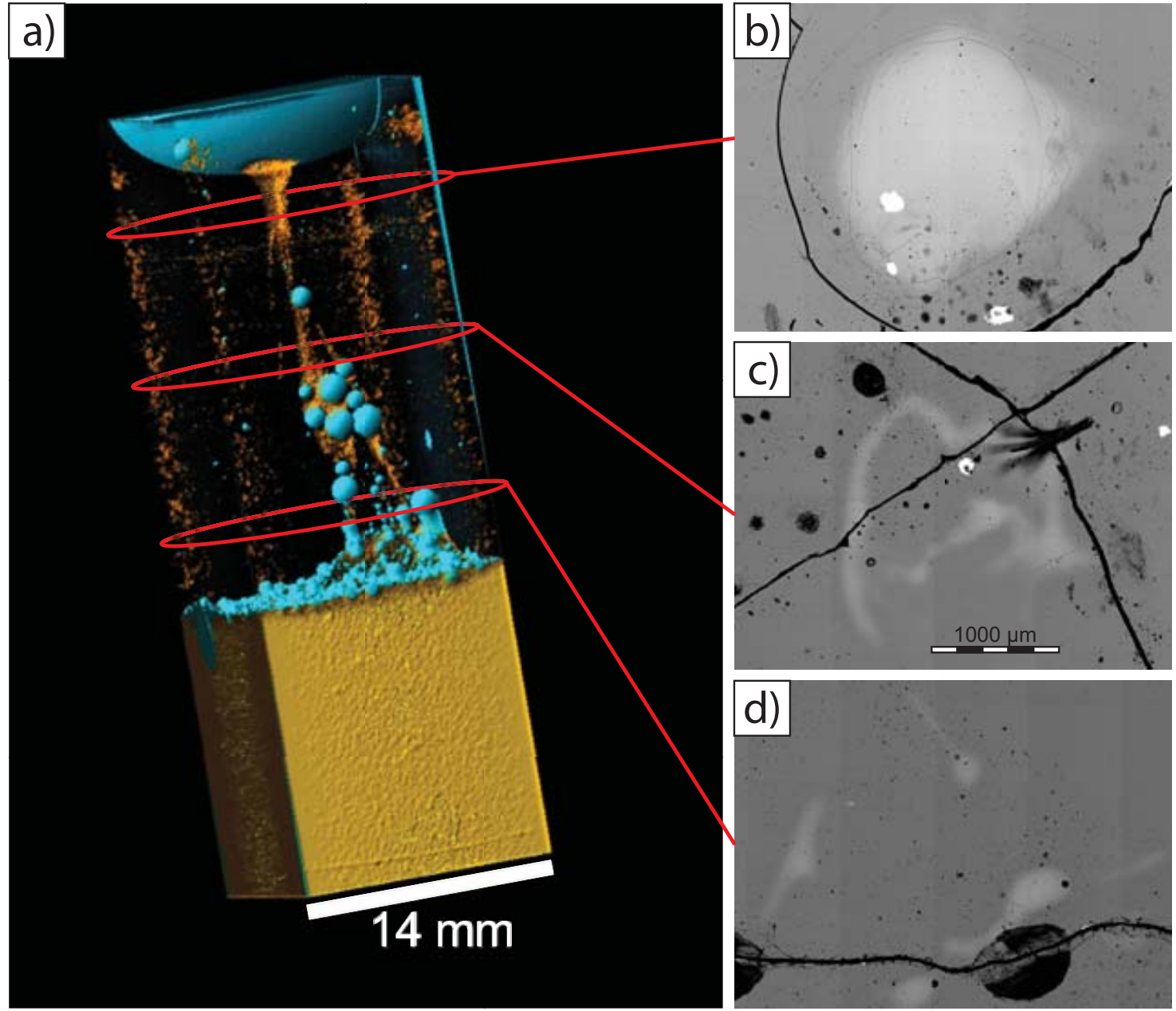

Figure 3. (a) 3-D representation of the experimental charge. The lower yellow layer is basaltic glass, whereas the upper rhyolitic layer has been rendered transparent. Hybrid material was rendered orange as a result of differing attenuation behaviour. The experimental charge has subsequently been sectioned parallel to the basalt-rhyolite interface at three levels, indicated by the red ellipses. The resulting cross sections of the filament structures are shown as backscattered electron images obtained from EMP analysis: (b) SWM-01, (c) SWM-02, and (d) SWM-03.

gradient part of the model filament (shaded red in Fig. 2b). Filament thickness was then varied by adding end-member data points in the plateau of the diffusion profile. The justification for this is that at time $i$, a species $s$ will have diffused the same distance away from the filament, irrespective of filament thickness. Thickness of the model filaments was determined following the approach outlined in Sect. 3.5 (see also Fig. 2b). This approach was repeated for diffusion times of $10,100,1000$, and $10000 \mathrm{~s}$. A minimum filament thickness results from this, as the diffusion gradient for each diffusion time possesses a finite length that contributes to the overall filament thickness. Finally, concentration variance was calculated for each modelled diffusion profile, and correlated with filament thickness.

\section{Results}

\subsection{MicroCT images}

\subsubsection{Bubbles}

Bubbles were arrested in their upwards motion at various levels in the experimental charge (Fig. 3a). At the bottom of the rhyolite, which has been kept transparent for illustrative purposes in Fig. 3a, there is a horizon of ca. 50 bubbles ( $<0.5 \mathrm{~mm}$ radius), some of them in the act of penetrating the rhyolite. Their small radii (measured in the 3-D software) indicate very slow ascent speeds after Stokes' law and consequently negligible motion over the experimental run time of $3 \mathrm{~h}$. Their position is thus consistent with formation at the interface between basalt and rhyolite. Bubbles further up 
Table 2. Compilation of measured radii of bubbles suspended in rhyolite glass. Ellipsoid radii r1, r2 and r3 are given, along with normalised radii and sum of normalised radii.

\begin{tabular}{lccccccc}
\hline & \multicolumn{3}{c}{ Ellipsoid radii [voxel] } & \multicolumn{3}{c}{ Normalised radii [dim.less] } \\
\cline { 2 - 8 } Bubble ID & r1 & r2 & r3 & r1_norm & r2_norm & r3_norm & total \\
\hline 1 & 16.35 & 15.94 & 15.59 & 0.34 & 0.33 & 0.33 & 1.00 \\
2 & 19.81 & 19.65 & 19.28 & 0.34 & 0.33 & 0.33 & 1.00 \\
3 & 14.11 & 13.79 & 13.37 & 0.34 & 0.33 & 0.32 & 0.99 \\
4 & 10.18 & 9.42 & 9.26 & 0.35 & 0.33 & 0.32 & 1.00 \\
5 & 14.36 & 14.06 & 13.78 & 0.34 & 0.33 & 0.33 & 1.00 \\
6 & 6.31 & 5.79 & 5.55 & 0.36 & 0.33 & 0.31 & 1.00 \\
7 & 8.25 & 8.04 & 7.87 & 0.34 & 0.33 & 0.33 & 1.00 \\
8 & 9.31 & 9.17 & 9.02 & 0.34 & 0.33 & 0.33 & 1.00 \\
\hline
\end{tabular}

(within the rhyolite) exhibit orange tails (filaments). Bubbles without filaments are interpreted to have entered the rhyolite from the sidewall of the rhyolite charge. Bubbles with a filament attached at their bottom must have been in contact to basaltic melt during their ascent. Hence, we have clear evidence that advection of low-viscosity basaltic melt by gas bubbles into rhyolitic melt occurred. Several bubbles of up to $1.1 \mathrm{~mm}$ radius are embedded in a curved path of filaments. Because of the curvature of the filaments, the bubbles probably formed at the bottom between the crucible wall and the basalt, and traversed the circular basalt-rhyolite interface offcentre. The large bubble at the top has broken the open surface of the rhyolite and probably represents coalescence of many smaller bubbles. Aspect ratios of bubbles suspended in rhyolite have been calculated. For this, only bubbles not in the process of coalescence and enough distance away from other bubbles or the basalt-rhyolite interface have been considered for the measurement of aspect ratios. Measured bubbles $(n=8)$ were near-equant, with the normalised radii of individual ellipsoids being close to a perfect sphere distribution of $33 \%$ per radius (Table 2 ).

\subsubsection{Filaments}

The reconstructed 3-D volume from the microCT scans shows sub-vertically oriented elongate structures and filaments, attached to the bottom of several bubbles (Fig. 3a). Apart from this, where bubbles appear to be free of films of mafic or hybrid material around them, the gap thickness is consequently zero. The filaments have grey-scale values intermediate to those of the basalt and the rhyolite glass, indicative of compositional interaction between basalt and rhyolite.

In the cross section, these hybrid filaments appear at the top in the form of a thick cylindrical filament attached to the bottom of the topmost bubble (Fig. 3b). About $5 \mathrm{~mm}$ deeper, the thick filament fans out into multiple filaments of several hundreds of micron thickness (Fig. 3c). Yet deeper, several discrete filaments of sheet-like geometry are visible (Fig. 3d). Filaments therefore seem to have merged together onto a large filament during bubble motion from bottom to top.

Some artefacts are observed in the 3-D volume. The basalt in yellow appears to feature a grainy texture, caused by the segmentation process in the software. Nevertheless, the glass has been confirmed to be homogeneous in thin section. Another artefact is indicated by the orange voxels along the vertical edges of the 3-D cuboid. The original experimental shape was of cylindrical shape, but displayed a circumferential interference interpreted as beam hardening. To clarify the 3-D volume for visual inspection, the cuboid shape was chosen to free the sides of the sample from visual obstruction.

\subsection{Composition of experimental glasses and diffusion profiles}

After 3-D tomography, the glass cylinder was sectioned parallel to the basalt-rhyolite interface (see Fig. 3a). This permitted us to obtain three cross sections through the vertically oriented filaments of mafic melt. Backscattered electron (BSE) images of these three cross sections are shown in Fig. 4. The uppermost level, SWM01, features a basaltic area of sub-spherical shape of ca. $2.5 \mathrm{~mm}$ diameter (Fig. 4a). The intermediate level SWM02 shows a convoluted, but coherent single filament (Fig. 4b). The lowest level SWM03 appears as three or four separate filaments of varying thickness (Fig. 4c). The EMP transects carried out for each cross section are indicated by yellow lines in Fig. 4. The single filament in sample SWM01 required one transect only (SWM01-01), whereas the more convoluted filament structures of SWM02 and SWM03 were characterised by four EMP transects each (see labels in Fig. 4). The compositional profiles of each filament displayed three distinct shapes: bellshaped, plateau-shaped and multi-peak/irregular shape.

\subsubsection{Section SWM01}

The transect across the sub-circular filament of SWM01-01 covers a distance of ca. $2800 \mu \mathrm{m}$ (Fig. 4a). Diffusion profiles of all major elements are symmetric and plateau-shaped. On 

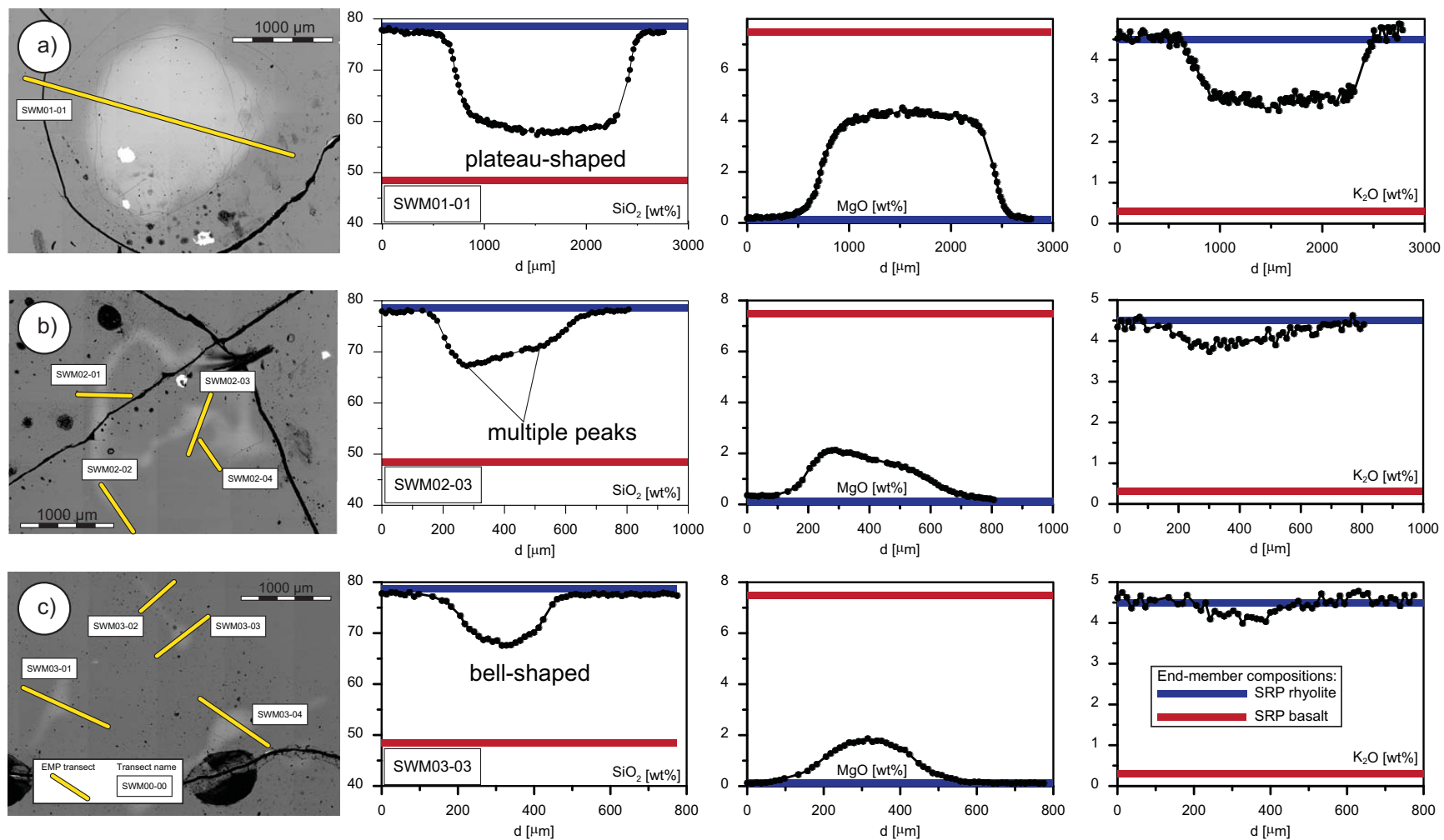

Figure 4. Backscattered electron images of horizontal sections of experimental glass. (a) Uppermost, (b) intermediate and (c) lowermost section of the rhyolite glass (dark grey), which contains horizontally sectioned magmatic filaments in light grey. Yellow lines indicate the locations of the EMP transects. Please refer to Fig. 3 for the exact vertical location of each section. The BSE images are complemented by representative major element concentration profiles. Blue and red lines indicate the initial compositions of the end-members basalt and rhyolite.

either side, ca. $500 \mu \mathrm{m}$ of pristine rhyolite has been measured before the profile grades to more mafic composition. These gradients, one from either side, cover variable distances depending on the element measured and are between 100 and $400 \mu \mathrm{m}$ long (Fig. 4a). The middle section of the analytical transect is relatively flat. There, the most mafic composition of the profile is detected, bordering the fields of andesite and trachyandesite (Fig. 5).

\subsubsection{Section SWM02}

SWM02-01: the profile of SWM02-01 is sub-symmetrically bell-shaped for most major elements, but, compared with SWM01-01, shows a much smaller compositional span. The most "mafic" composition detected is low- $\mathrm{SiO}_{2}$ rhyolite. $\mathrm{Na}_{2} \mathrm{O}$ appears overlain by the analytical error, and $\mathrm{K}_{2} \mathrm{O}$ measurements exceed the concentration expected for the rhyolite.

SWM02-02: as other transects, this EMP transect started in glass of rhyolitic composition. However, the transect is asymmetric and recorded more mafic glass at the other end. This precluded certainty of having measured the most mafic composition in the filament. SWM02-02 is therefore excluded from further interpretation.
SWM02-03: shows two peaks in all element profiles (Fig. 4b). Probably, two separate filaments of either different thickness or different time of hybridisation are combined in the analysed filament. A useful estimation of diffusion rates is thus hindered in transect SWM02-03, which is consequently excluded from the interpretation of diffusion profiles.

SWM02-04: the diffusion profiles are bell-shaped, but of little amplitude. In the TAS diagram, all data points cluster very near the original composition of the end-member rhyolite. In such cases, the analytical error was significant in the variation of $\mathrm{Na}_{2} \mathrm{O}, \mathrm{K}_{2} \mathrm{O}$, and $\mathrm{TiO}_{2}$ concentrations, which affects the calculation of concentration variance values.

\subsubsection{Section SWM03}

SWM03-01: the profiles appear similar to SWM02-04 with very little variation and all data points group very near the original composition of the end-member rhyolite. Again, the analytical error may be significant in the variation of $\mathrm{Na}_{2} \mathrm{O}$, $\mathrm{K}_{2} \mathrm{O}$, and $\mathrm{TiO}_{2}$ concentrations.

SWM03-02: most profiles are sub-symmetrically bellshaped, and span a compositional range of rhyolite to dacite/trachyte. Again, $\mathrm{Na}_{2} \mathrm{O}$ data appear affected by the an- 


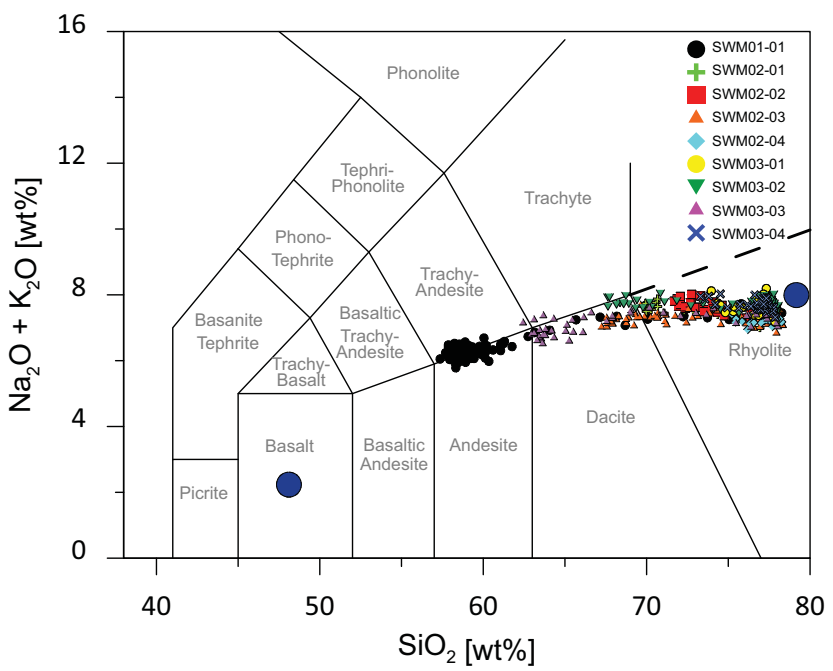

Figure 5. TAS plot of end-member compositions and hybrid compositions produced during the bubble advection experiment. Data normalised to $100 \%$ totals. Blue and red circles denote the endmember compositions of Snake River basalt and rhyolite. Nonlinearity of trend is due to diffusive fractionation of Na vs. K (see Perugini et al., 2006, 2008; De Campos et al., 2008).

alytical error and $\mathrm{K}_{2} \mathrm{O}$ measurements exceed the concentration expected for the rhyolite.

SWM03-03: shows sub-symmetrical bell-shaped profiles, which amount to rhyolitic to trachyandesitic composition (Fig. 4c). Also here, the profile of $\mathrm{Na}_{2} \mathrm{O}$ seems affected by the analytical error and $\mathrm{K}_{2} \mathrm{O}$ data are higher than expected for the rhyolite.

SWM03-04: profiles appear bell-shaped, but, as for some of the previous transects, with very little compositional variation. In the TAS diagram, all data points group very near the original composition of the end-member rhyolite. The analytical error was significant in $\mathrm{Na}_{2} \mathrm{O}, \mathrm{K}_{2} \mathrm{O}$ and $\mathrm{TiO}_{2}$.

In summary, analytical transects may be grouped as follows; (a) bell-shaped (SWM02-01, SWM02-04, SWM0302, and SWM03-03), (b) plateau-shaped (SWM01-01), and (c) multi-peak/irregular (SWM02-02, SWM02-03, SWM0301, and SWM03-04) (see Fig. 4). Common to all of the nine analysed filaments is that the basaltic end-member is not preserved. Diffusive equilibration was thus pervasive for all filaments.

\subsection{Results of model filament calculation}

In model filament calculations, concentration variance correlates systematically with filament thickness. In Fig. 6, each curve represents concentration variance vs. filament thickness at a specified diffusion time. Concentration variance, i.e. the degree to which filament with thickness $x$ has equilibrated, correlates non-linearly with filament thickness. At a particular diffusion time, thin filaments will be much more

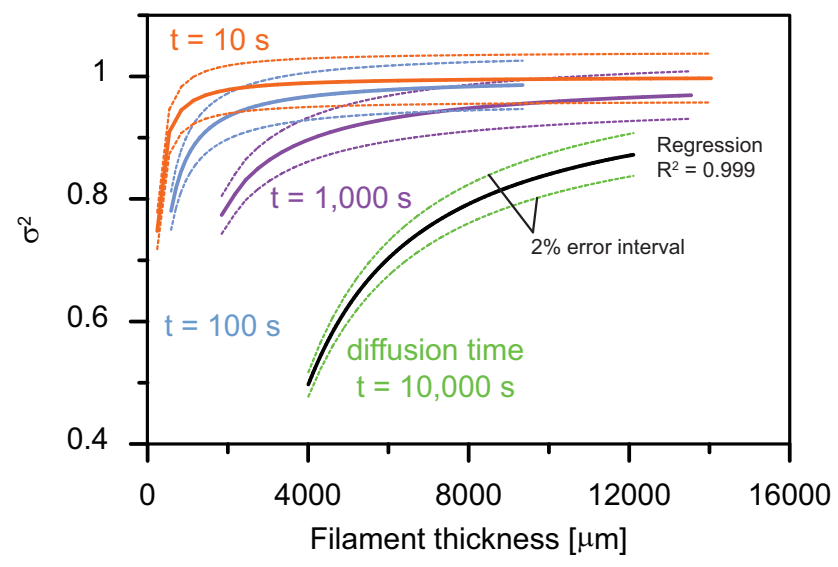

Figure 6. Ideal behaviour of concentration variance depending on filament thickness. Each data point represents the concentration variance of an entire diffusion profile correlated with the filament thickness of that profile. Four curves were calculated for different diffusion times, which are indicated in the graph. Each curve shows a $2 \%$ error interval (dotted lines).

homogenised (lower value of concentration variance $\sigma^{2}$ ) than thick filaments (cf. Morgavi et al., 2013c).

Because the curves possess steeper slopes towards thin filament thickness, thin filaments equilibrate disproportionally faster than thick ones. When we compare curves of different diffusion time, the contrast between thick and thin filaments decreases with increasing diffusion time, but the overall non-linearity remains. For instance, for the curve in Figure 6 with the longest diffusion time modelled $(10000 \mathrm{~s})$, a $8000 \mu \mathrm{m}$ thick filament shows a $\sigma^{2}$ of $\sim 0.8$, whereas a filament of $4000 \mu \mathrm{m}$ has $\sim 0.5$. Hence, half the filament thickness allowed diffusive equilibration to complete $50 \%$ instead of $20 \%$ in the same time. By reducing filament thickness by a factor of 2, the efficiency of diffusive equilibration was increased by a factor of 2.5. As the slope of all curves in Fig. 6 show steeper slopes for thinner filaments, the rate of diffusive equilibration is higher for thinner filaments. This means that also the difference in equilibration rate between two filaments is higher when both are relatively thin.

Polynomial regressions allow us to further characterise the model of diffusive equilibration. All calculated regressions have $R^{2}>0.998$. The asymptotic nature of the regression curves implies that its first derivative approaches zero at infinite filament thickness. Large magmatic bodies are thus very inefficiently equilibrated by diffusion alone. The nonlinearity of the regression curves is thus evidence for an exponential increase in the rate of equilibration with decreasing filament thickness.

\subsection{Filament rheology}

We calculated viscosities of hybrid filaments based on compositions measured by EMP. The initial viscosity contrast of 
the pure end-member was measured to be a factor of $4 \times 10^{3}$ (cf. Morgavi et al., 2012). By employing the viscosity model of Giordano et al. (2008), the EMP compositional data were converted into melt viscosities of the filaments. As the most mafic composition of each individual filament varies, the computed minimum viscosities for the filaments range between ca. $10^{1.5}$ and ca. $10^{3.5} \mathrm{~Pa} \mathrm{~s}^{-1}$. Under the experimental conditions $\left(1\right.$-atm, $\left.1450^{\circ} \mathrm{C}\right)$, the rhyolitic end-member possesses a calculated viscosity of ca. $10^{3.8} \mathrm{~Pa} \mathrm{~s}^{-1}$, compared to a measured $10^{4} \mathrm{Pas}^{-1}$. Viscosity contrasts between rhyolitic and hybrid melt thus range between a minimum factor of 3 to in excess of 100 .

\section{Interpretation and Discussion}

\subsection{3-D image and continuum mechanical appraisal of the experimental sample}

The imaging results from microCT reveal that multiple bubbles have risen through the rhyolite, dragging portions of basaltic melt upwards with them (see Fig. 3). These subvertical elongated filaments are thoroughly hybridised, according to microCT attenuation values and EMP data. Because several hybrid filaments merged into one thicker filament underneath the topmost bubble, bubbles appear to have exploited the same pathway repeatedly. The experimental setup has thus generated two main modes of mass transport. Firstly, advection of basaltic into rhyolitic melt driven by the segregation of bubbles. Secondly, diffusion of ionic species across the boundary between basalt and rhyolite melts. This experiment therefore demonstrates the potential for bubble mixing at viscosity contrasts of up to $4 \times 10^{3}$.

Several implications arise from comparison of our experiment to the numerical analysis of migration of drops through fluid-fluid interfaces (Manga and Stone, 1995). Based on numerical constraints, Manga and Stone (1995) suggested that the volume of entrained fluid decreases with increasing ratio of upper to lower fluid viscosity $\gamma$. As our experiment constitutes a case of high $\gamma\left(\mathrm{ca} .4 \times 10^{3}\right)$ the entrained volume of basaltic melt should be low, perhaps insignificant. However, according to the microCT image, significant amounts of basaltic melt have been propagated, which either indicates that the volume of entrained fluid never reaches 0 even at high-viscosity contrasts, or the higher value of $\beta(0.2$ in Manga and Stone, 1995, vs. 0.79 in the experiment) causes a relatively higher buoyancy of the bubble in rhyolite to still permit significant volumes of entrained melt.

The time of penetration of a bubble into the upper layer, or breaking the interface between basaltic and rhyolitic melt, scales at a factor of approximately $1 /(1+\lambda)$ of the ascent rate, where $\lambda$ is the ratio of bubble to lower fluid viscosity (Rallison, 1984; Kojima et al., 1984). For our experiment, the large viscosity contrast of air and basaltic melt at $1723 \mathrm{~K}$ implies a $\lambda$ of around $2.35 \times 10^{-5}$, meaning the ascent rate of bubbles would hardly be affected by the interface and bubbles essentially pass through with nearly no deceleration from the interface (i.e. only the buoyancy change affects the rise speed). This is consistent with Manga and Stone (1995, Fig. $8 \mathrm{~d}$ therein, $\lambda=10$ ), where the rise speed decreases continually upon entering the higher viscosity upper liquid, but potential interface effects in the form of a rise speed minimum are not detected.

Discrepancies between our experiment and the numerical treatment of Manga and Stone (1995) arise with respect to the Bond number and surface tension. The surface tension of dry silicate melt against a free vapour phase is an order of magnitude higher than the surface tensions employed for the fluids in the analogue experiments of Manga and Stone (1995). In the present case, the bubble Bond number $B o_{1}$ is below 1, whereas Manga and Stone (1995) addressed problems of $B o_{1}>5$. Smaller Bond numbers imply that bubble shape is surface tension-controlled and deformation of bubbles in the rhyolite is limited. Consistent with that, the measured aspect ratios of bubbles are close to being equant.

Specific to bubble mixing is that successive bubbles may repeatedly advect mafic material into the same filament. A filament may thus experience mafic recharge at irregular frequency. This gives rise to a complex diffusion scenario, because the composition of the filament may be hybridised initially, but reset to a more mafic composition repeatedly. Additionally, as later pulses of basalt may traverse a filament of already hybrid composition, these later pulses may equilibrate at variable rates due to the reduced compositional contrast they experience. As a result, not only the mode of advection is non-conventional (bubbles instead of inherent buoyancy or convection), but also the calculation of diffusion timescales must take into account; additional mafic melt of variable composition may or may not have been added to a filament at later stages.

\subsection{Rheology of hybrid filaments}

The compositional variations across the filaments imply a dynamic rate change for bubble mixing. The viscosity contrast from basalt to hybridised filament is smaller than from basalt to pristine rhyolitic melt. Figure 7 shows this "viscosity valley" in the interior of filaments compared to the surrounding rhyolite. Computing the $\log$ viscosities, the maximum viscosity contrast $\gamma$ at $t=0$ was 4000 and at $t=3 \mathrm{~h}$ is reduced to ca. 32 for filament SWM01-01 $\left(\gamma_{i}=10^{1.5} / 10^{0.4}\right)$. Envisaging a constant flux of bubbles, this means that when the rhyolite has been penetrated by filaments throughout, bubbles will inevitably enter these previously formed filaments for their reduced viscous resistance against the buoyancy forces of a bubble.

The ramifications of low-viscosity channels for the process of bubble mixing are manifold. First of all, higher ascent velocities are expected for bubbles that rise within a filament, as Stokes' Law velocities are proportional to 1/vis- 

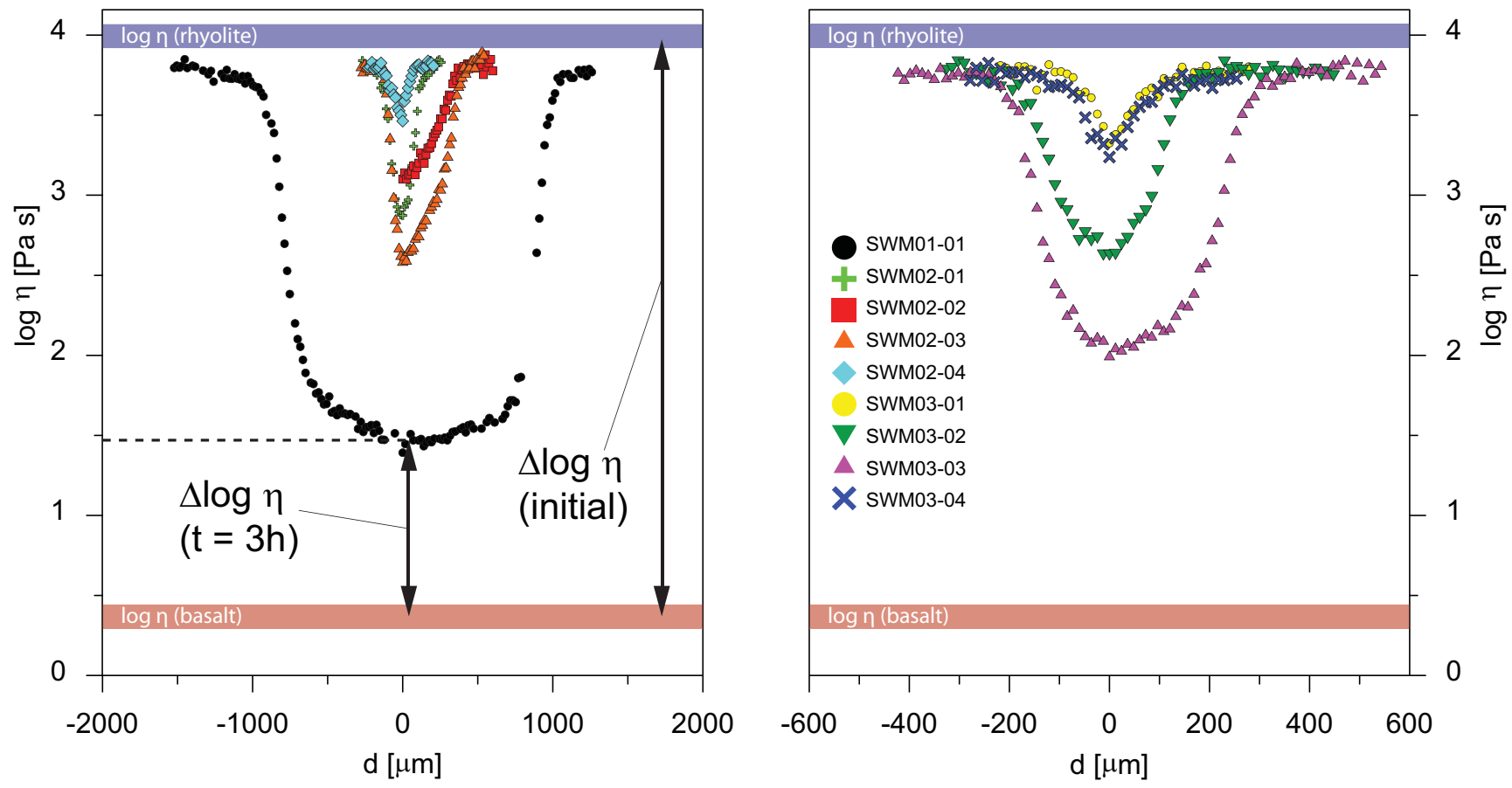

Figure 7. Modelled viscosity of filament compositions after Giordano et al. (2008), with two panels for clarity. The procedure to calculate viscosity contrast for each filament is indicated by the two arrows $\left(\Delta \log \left(\eta_{0}\right)-\Delta \log \left(\eta_{3 h}\right)\right)$.

cosity. Therefore, at the calculated filament viscosity of ca. $10^{1.5} \mathrm{~Pa} \mathrm{~s}^{-1}$ (compared to $10^{4} \mathrm{~Pa} \mathrm{~s}^{-1}$ in the rhyolite), the terminal settling speed of a bubble may be up to 300 times faster in a hybrid filament than through pristine rhyolite. This is certainly a maximum estimate, as streamline geometry and the ratio of bubble to filament diameter will also affect rise speed. Notwithstanding, compared to pristine rhyolite, the reduced viscosity of a hybrid filament inside a rhyolite must enhance the rate of bubble ascent significantly. Secondly, the initial ratio of viscosities of upper to lower fluid $\gamma$ affect how much basaltic melt can be advected. According to Manga and Stone (1995), $\gamma$ inversely correlates with the amount of lower fluid entrained into the upper liquid. For filament SWM01$01, \gamma$ changed from $4 \times 10^{3}$ down to 13 , implying an increase in transported material. When a bubble enters a hybrid filament, it may thus be able to propagate larger amounts of basaltic liquid than upon entering pristine rhyolite. This affects the mixing rate once more, as more material per bubble is being advected. Thirdly, the buoyancy change $\beta$ that the bubble experiences upon entering the upper fluid will be diminished. Calculation of $\beta$ using the viscosity of the hybrid filaments implies a reduced buoyancy change (from 0.8 to 0.9 ), because the hybrid filament has a higher density than the surrounding rhyolite. The higher value of $\beta$ implies lesser deceleration of the ascent speed caused by the viscosity contrast. Not only does the rise speed within the rhyolite increase, but also the rise speed through the basalt-rhyolite interface.
The last point to consider is filament geometry. The uppermost filament from our experiment SWM-01 shows visual and compositional evidence for its formation by many pulses of mafic melt, which likely caused the disproportionate thickness of this filament. Filaments are thus widening due to addition of new mafic melt by each passing bubble. However, when the repeated advection of basalt through a filament thickens that filament, bubble advection will be enhanced as the diameter of the low-viscosity channel is enlarged. This represents a positive feedback loop, as a widened filament diameter enhances bubble ascent, which in turn widens filaments even more. Additionally, we speculate that recurring bubble advection may create a network of hybrid filaments by coalescence of bubbles and merging filaments.

The acceleration of the rate of mixing may in theory continue until filaments purely consist of mafic end-member, at which point the lowest possible viscosity is established inside the filament. By then a steady state would be reached and new mafic material advected at a constant rate per bubble and bubble size. Once the source reservoir of the mafic end-member is depleted of a free gas phase, mixing induced by bubbles must decelerate until more volatiles are exsolved or external volatile sources are tapped.

\subsection{Detection of multi-pulse filaments}

We present a method to detect multi-pulse filaments in natural samples. The 3-D visual evidence demonstrates that multi-pulse filaments are present in our experimental run 
products. Nevertheless, in natural samples, 3-D visual evidence may not be as clear cut as here. We thus aim to constrain the origin of filaments further by a statistical treatment of the compositional profiles obtained from EMP analysis.

In the context of our experimental setup, single-pulse filaments are expected to stretch out from the basalt-rhyolite interface towards the top of the rhyolite, as one bubble moves upwards within the rhyolite. Diffusional equilibration for single-pulse filaments thus ought to shift systematically from high degrees of equilibration at the bottom of a vertical, cylindrical filament to fewer degrees of hybridisation at the top. Such systematic correlation of diffusionbased equilibration with vertical position would be useful for constraining the timescales of filament formation, but is not detected on our experimental filaments. Instead, rheologic and visual constraints indicate that experimental filaments formed by bubble mixing experienced multiple bubbles rising. Such repeated replenishment of multi-pulse filaments with fresh end-member melt must affect the diffusional equilibration from previous pulses, though. Multi-pulse filaments are thus expected to significantly deviate in their diffusional behaviour from single-pulse filaments. This is important because the calculation of magmatic timescales based on diffusion gradients has commonly been based on a single-pulse origin of magmatic filaments, bar other options recognised so far. It is thus vital to be able to distinguish single- from multi-pulse filaments in natural samples.

The characteristics of our experimental charge are advantageous for distinction of single- and multi-pulse filaments, as it is comparable to natural samples in key aspects. Firstly, bubbles were allowed to rise in uncontrolled fashion. The resulting filaments are therefore a result of the conditions in situ within the experimental charge, and mainly controlled through the parameters buoyancy, surface tension and rheology. Secondly, the time evolution of the experiment is uncontrolled except for the total run time. As direct observations during the experiment were inhibited, the formation of filaments has to be constrained a posteriori, comparable to natural samples. Our experimental design thus mimics natural samples in these aspects, while on the other hand has the advantage that pressure, temperature, and initial end-member compositions are known. This allows us to constrain the origin of the filaments generated during the experiment to a degree much further than is possible in natural samples.

\subsubsection{Compositional profiles of filaments indicate their formation mechanism}

The shape of compositional profiles obtained from filaments allows a qualitative estimation of filament formation. Three different shapes of compositional profiles have been observed: (a) multi-peak or irregularly shaped, (b) plateaushaped, and (c) bell-shaped (see Fig. 4).
1. Multi-peak or irregular shapes of analytical profiles are not explicable by standard diffusion models and have most likely been affected by multiple bubbles having risen through (see Fig. 4b).

2. Plateau-shaped profiles (see Fig. 4a), in turn, permit both possibilities, single- and multiple-pulse origin. If the original end-member composition is preserved in the plateau of the profile, then standard diffusion theory applies, and a single-pulse origin is probable. Should the plateau lie at a hybrid concentration between both end-members, it must be the result of multiple pulses as the comparison with a single-pulse filament shows. In a single-pulse filament, its centre can only be hybridised after the plateau has been obliterated by diffusion. Filament SWM01-01 shows a compositional profile that is both a plateau and of hybrid composition (see Fig. 4a) and is thus interpreted as having a composite structure of multiple filaments. This multi-pulse origin of filament SWM01-01 is also confirmed by microCT imaging, which shows several bubble trails (filaments) converging to the final filament (see Fig. 3).

3. Bell-shaped profiles (see Fig. 4c) are ambiguous in the context of our experiment. On one hand, these analytical profiles approach a Gaussian distribution, presumably indicative of a single-pulse origin. However, 3-D data also indicate a multi-pulse origin for several of these.

The analysis of compositional profiles of the magmatic filaments from this experiment raises the question: has a filament been produced by a single pulse of magma (in the case of this experiment, this would translate to a single bubble), or have multiple pulses been involved? The answer to this question is relevant as the notion of multi-pulse filaments is quite uncommon in igneous petrology. To date, in studies on magma mixing, magmatic filaments are assumed to result from one single pulse of magma. Filaments may be stretched and folded ad infinitum, but are assumed never to be replenished by fresh mafic magma. Here, bubble mixing challenges this assumption. If multiple bubbles are involved then analytical profiles of such filaments, used for the calculation of diffusional timescales, will yield erroneous results. We therefore propose the following method for distinction of single- and multi-pulse filaments.

\subsubsection{The distinction of single- and multi-pulse filaments}

We have devised a method to distinguish the single vs. multiple origins of filaments based on EMP data statistically. Do filaments that feature bell-shaped compositional profiles have a complex history of formation? We compare the values of concentration variance from our experimental filaments with theoretical values computed from ideal "model filaments" (see Sect. 3.7). The model filaments have been 


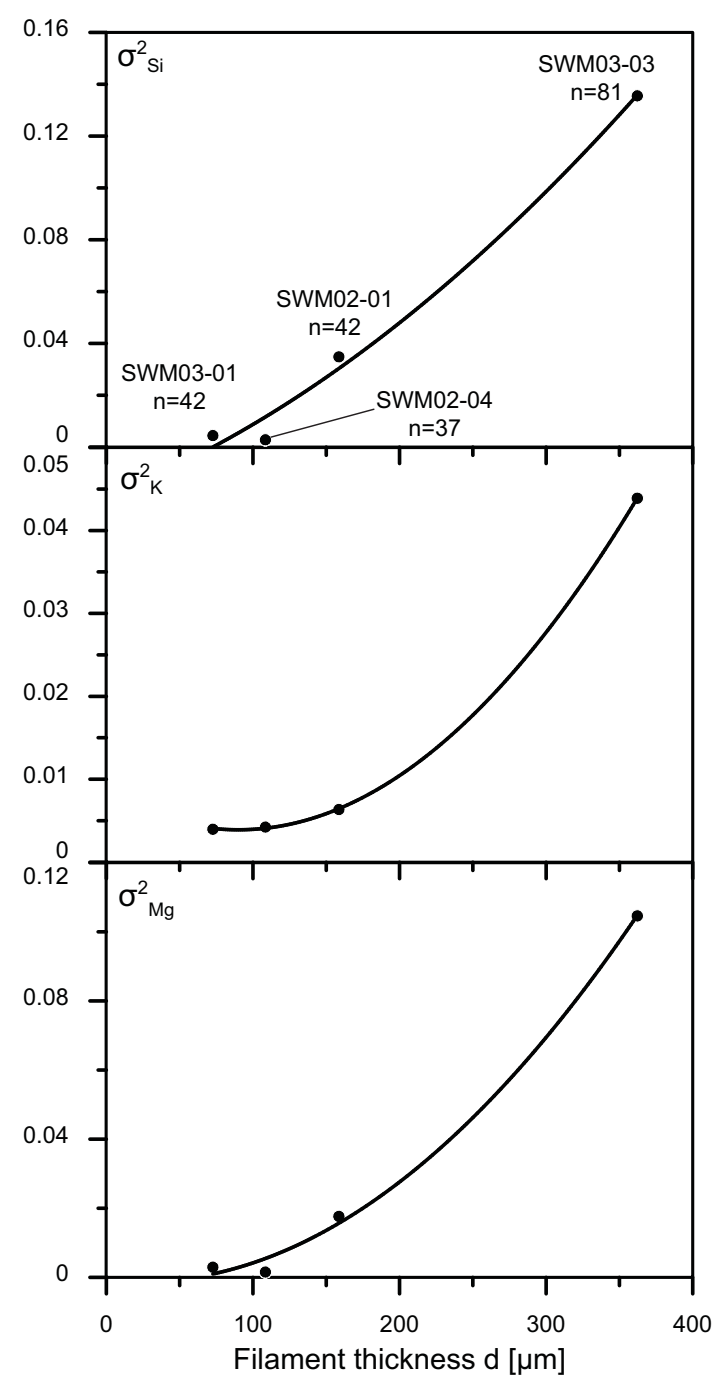

Figure 8. Concentration variance of experimental filaments vs. filament thickness for experimental filaments that yielded compositional profiles of bell-shape. The best-fit regression curves for the experimental filaments are polynomial and yield high $R^{2}$ values. The four data points represent four analytical transects of 202 EMP data points altogether.

calculated with boundary conditions consistent with our experimental setup. They have been modelled as single-pulse filaments, and thus characterise the diffusive equilibration of individual filaments under ideal conditions. The comparison was carried out between model filaments and those experimental filaments with bell-shaped compositional profiles (SWM02-01, SMW-02-04, SWM03-02, and SWM03-03).

Figure 8 shows concentration variance vs. filament thickness for the four bell-shaped compositional profiles from the bubble-mixing experiment. The regression curves of their concentration variance $\sigma^{2}$ have opposite curvature (downwardly convex) to the single-pulse modelled data (upwardly convex; see Fig. 6). This systematic dissimilarity indicates that equilibration behaviour for the experimental filaments was fundamentally different compared to single-pulse filaments. This qualitative argument becomes more obvious when considering specific data points. Data points SWM0301 and SWM02-04 are from filaments of different thickness, but show very similar values of concentration variance $\sigma^{2}$, for example for potassium (Fig. 8, second panel). However, a single-pulse origin would predict distinct values of $\sigma^{2}$ for filaments of different thickness. Especially for these very thin filaments the single-pulse regression curve ought to slope steeply, meaning a pronounced difference in $\sigma^{2}$ is expected (see Fig. 6). As the regressions in all major elements for the entire set of experimental filaments shows opposite curvature compared to the single-pulse case, more than one multi-pulse filament must be present in this set. The visual observations from 3-D microCT analysis confirm this notion of multiple thin filaments converging to larger ones and therefore support the validity of correlating filament thickness with concentration variance to distinguish single- and multi-pulse filaments. We therefore conclude that the proposed statistical treatment of compositional data of magmatic filaments is useful to constrain their formation mechanism. This is important as the exact mechanisms, time evolution and conditions of formation are essentially unknown for any natural sample. Therefore, magmatic filaments and their observed compositional patterns need to be tested for whether bubbles have played a role for magma mixing.

\subsection{Relevance for natural scenarios}

Is bubble mixing relevant in nature? Each natural case represents a unique combination of extrinsic and intrinsic properties, all of which influence whether bubble mixing comes into play during a system's magmatic history. In the following, we will lay out scenarios in which volatile content, thermal history, and viscosity contrast may be favourable for bubble mixing. We then conclude with evidence from natural case studies that may show an influence of bubble mixing.

\subsubsection{Effects of variable temperature conditions on bubble mixing}

Temperature contrasts between mafic and felsic magma are expected in nature. This merits the question whether or not a mechanism such as bubble mixing may be inhibited by quenching of one magma against another. Quench textures form when e.g. a hot basaltic magma is juxtaposed on a much cooler, felsic magma and usually occur as mafic enclaves with chilled margins, as finely-grained dyke margins or even as mafic foam (e.g. Eichelberger, 1980; Coombs et al., 2003). The timescales of interaction are short, because steep temperature gradients and small volume of individual enclaves cause the mafic enclave to rapidly solidify and quench.

However, the presence of magmatic filaments in many outcrops worldwide testify to the potential of two magmas of 
contrasting composition to interact in fluid mechanical fashion (e.g. Perugini et al., 2002). In every one of these cases, thermal equilibration must have occurred to some degree, so as to inhibit quenching and permit magma mingling. Especially striking is the case of Montaña Reventada in Tenerife, Spain, where evidence for quenching and fluid-fluid interaction are simultaneously present in a composite lava flow from a single, monogenetic eruption. In the phonolite member of the Reventada flow, hybrid inclusions quenched to different degrees are observed, right next to hybrid filaments, which in turn are indicative of magma mingling. The variety of textures detected in the basanite inclusions and filaments has been interpreted to reflect a progressive thermal equilibration between mafic and felsic magma (Wiesmaier et al., 2011). As this thermal equilibration is thought to have occurred on a short timescale just prior to eruption, the case of Montaña Reventada provides an example of how rapidly a natural system is able to move from production of quench textures to fluid-fluid interaction. Therefore, quenching of two magmas against each other has to be regarded as highly transient process. In turn, bubble mixing may occur soon after the onset of thermal equilibration, specifically when the temperature contrast is already too low for quenching. The problem then becomes one of (a) potential onset of convection in the magma chamber and (b) the initial viscosity contrast between the two magmas. Convection in a magma chamber depends on many variables in a natural system and, when occurring, certainly hinders bubble mixing. In the context of bubble mixing, we thus focus on the initial viscosity contrast in the following.

\subsubsection{Initial viscosity contrast}

For our experiment, the furnace temperature was chosen to achieve a combination of feasible viscosity contrast, crystalfree melts and relatively short run time. Our experiment approximates the fluid dynamic behaviour of bubbles and attached filaments at an initial viscosity contrast $\gamma$ of as high as $4 \times 10^{3}$. In nature, the initial viscosity contrast between two magmas may be much reduced. A lower viscosity contrast would cause more favourable conditions for bubble mixing, because of the reduced initial viscous resistance and also an increased buoyancy parameter $\beta$ (see Sect. 3.2.1), which implies less buoyancy loss for a bubble entering the upper body of melt. Because we chose an extreme viscosity contrast for the experiment, the qualitative notions hold fast, and may even be more pronounced, for systems showing smaller viscosity contrast between the initial end-member magmas. Rising bubbles that advect melt of more mafic composition will produce filaments of that melt in an overlying melt. A reduced initial viscosity contrast $\gamma$ (e.g. between end-members basalt and andesite) will be yet more favourable for bubble mixing, because, with lower $\gamma$, the volume of entrained material and rise speed increase.

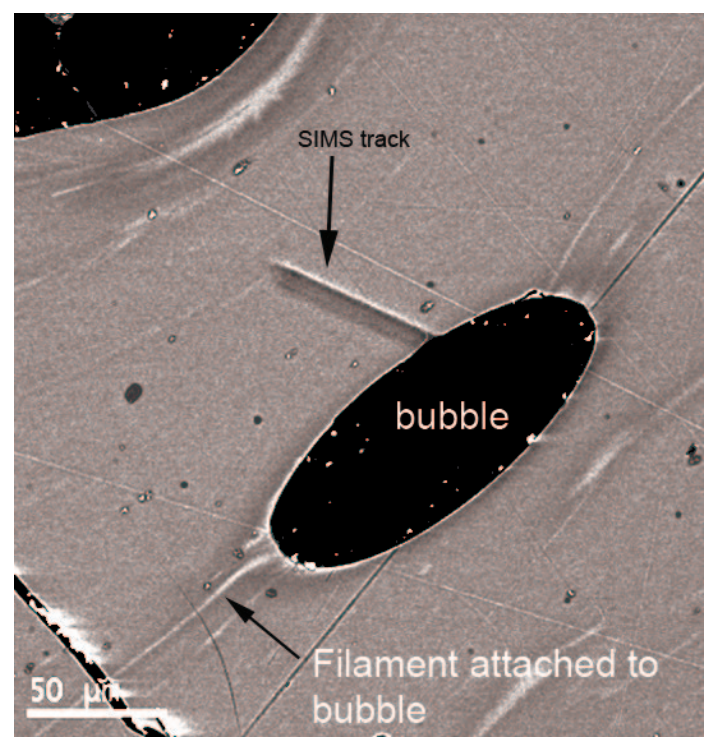

Figure 9. Backscattered electron images of basaltic glass from Axial Seamount (I. McIntosh, personal communication, 2015). Contrast enhanced for illustrative purposes. The red ellipse surrounds a filament (light grey) attached to a vesicle (black). The straight line away from the vesicle is the trace of a previous SIMS analysis for volatile species. Compositionally, EDX analysis shows the filament to be of more mafic composition than the surrounding glass (dark grey).

\subsubsection{Evidence for bubble action from natural case studies}

Bubbles have not been widely considered up to now as mixing agents. Here, we present natural scenarios pointing to the role of bubble ascent during the magmatic stage, along with first direct evidence from natural samples.

The Licán mafic ignimbrite, which erupted from the Villarica volcano, Chile, was potentially affected by a free volatile phase. Despite the homogeneity of this basaltic andesite, Lohmar et al. (2012) observed two distinct crystal populations with stark disequilibrium textures and overgrowth rims as hard petrological evidence for magma mixing. Mineralogical data and thermodynamic modelling indicate an increase of $\sim 200^{\circ} \mathrm{C}$ during petrogenesis, interpreted as mafic recharge and subsequent thermal equilibration. Additionally, the deposit features an extremely high vesicularity of $53 \mathrm{vol} \%$. The vesicularity of the deposit, uncommon in pre- and post-Licán deposits, is most certainly related to decompression-induced degassing. However, as the final vesicularity of the Licán mafic ignimbrite is unusually high for Villarica, the magma must have been very volatilerich prior to eruption. In combination with a relatively small temperature and viscosity contrast between the initial endmembers, the conditions in the Licán magma reservoir prior to eruption were thus highly favourable for mixing of the two magmas aided by bubbles. However, as the final deposit is 
very homogenous (apart from crystal populations), clear textural evidence pro or contra bubble mixing has probably been obliterated by the completion of mixing.

Direct evidence for bubble mixing is forwarded by samples from Axial Seamount. Backscattered electron images of samples from Axial Seamount show filaments of light material attached to vesicles (Fig. 9). Maps of energy-dispersive $\mathrm{X}$-ray spectra (EDX) show that these filaments have reduced $\mathrm{Si}$ and $\mathrm{Na}$ contents, together with increased $\mathrm{Fe}, \mathrm{Ca}$, and $\mathrm{Mg}$ contents compared to the surrounding basaltic glass (I. McIntosh, personal communication, 2015). The compositional data rule out volatile species such as $\mathrm{H}_{2} \mathrm{O}$ or $\mathrm{Cl}^{-}$in the observed filament structure. Magma mixing is probably common at Axial Seamount as shown by the variability in $\mathrm{MgO}$ content of Axial Seamount melt inclusions (Helo et al., 2011). As in this system mostly low-viscosity basaltic magmas occur, conditions are extremely favourable for bubble mixing. We suggest that this could be the first documented occurrence of bubble advection in natural volcanic material.

\section{Conclusions}

We conducted magma mixing experiments in which bubbles originating from a deep mafic melt intruded into a shallow felsic melt. The combination of tomographic and compositional evidence employed here has identified magma mixing induced by bubble advection. The results show that bubble ascent provides an efficient mechanism for hybridisation of contrasting melt compositions at extreme viscosity contrast of up to 4000 . Multiple bubbles were allowed to rise serendipitously from basalt to rhyolite, and subsequent bubbles were found to exploit filaments from previous bubbles as low-viscosity pathways.

Rheology and continuum mechanic arguments for the low-viscosity filaments indicate that bubble advection is enhanced by their presence. Once the first bubbles have formed filaments inside the rhyolite, the reduced viscosity inside these filaments causes

1. increased ascent speed of subsequent bubbles,

2. more basaltic fluid to be entrained per bubble,

3. accelerated traversal of the bubble across the basaltrhyolite interface, and

4. widening of filaments by addition of material from later bubbles further enhances bubble mixing.

Subsequent passage of multiple bubbles through a filament also implies mafic recharge of that filament. So far, magmatic filaments were tacitly assumed to be only of single-pulse origin, as conventional mechanisms of magma mingling (which stretch and fold magma) render replenishment of filaments unlikely. However, the potential multiple-pulse character of magma mixing filaments in natural samples means that diffusion profiles obtained from in situ analysis of magma-mixing filaments have to be tested for their origin. Multiple episodes of replenishment may have occurred in individual filaments, when a free gas phase was involved in their formation. We show a new method for distinction of single- from multipulse filaments. Based on in situ compositional data, correlation of concentration variance with filament thickness allows distinguishing whether a set of filaments formed conventionally by single pulse or multiple pulses of replenishment.

We propose that magma mixing induced by bubble advection may be a significant process in nature and may enhance the extent of mixing. Experimentally, this process has now been demonstrated to function under extremely highviscosity contrast. Samples from Axial Seamount show evidence for bubble mixing in nature. The reduced viscosity contrasts pertaining within such a mainly basaltic system will only facilitate bubble mixing. While effects of bubbles on the rheology of silicate are currently being researched, their fluid dynamic influence on the mechanic stirring of magma (mingling) has been demonstrated experimentally here.

Acknowledgements. We are greatly indebted to David Clague (MBARI), Christoph Helo (University of Mainz) and Iona McIntosh (JAMSTEC) for sourcing the information on the samples from Axial Seamount. Fabian Wadsworth helped with the calculation of heating rates. Two anonymous reviewers contributed by helpful and constructive comments. Funding for this project was provided by ICDP-DFG project number CA 905/1-1 and HE 4565/2-1, as well as DFG projects DI 431/31-1 and DI 431/31-2 and by the European Union's Seventh Programme for research technological development and demonstration under grant agreement no. 282759 - VUELCO. We wish to acknowledge the European Research Council for the Starting Grant SLiM (no. 306488) awarded to Y Lavallée, Consolidator Grant CHRONOS (no. 612776) to D. Perugini and Advanced Grant EVOKES (no. 247076) to D. B. Dingwell.

Edited by: N. T. Arndt

\section{References}

Bagdassarov, N., Dorfman, A., and Dingwell, D. B.: Effect of alkalis, phosphorus, and water on the surface tension of haplogranite melt, Am. Mineral., 85, 33-40, 2000.

Blake, S. and Campbell, I. H.: The dynamics of magma-mixing during flow in volcanic conduits, Contrib. Mineral. Petrol., 94, 7281, 1986.

Bonnichsen, B.: The Bruneau-Jarbidge Eruptive Center, Southwestern Idaho, in: Cenozoic Geology of Idaho, edited by: Bonnichsen, B. and Breckenridge, R. M., Idaho Bureau of Mines and Geology Bulletin, 237-254, 1982.

Cathey, H. E. and Nash, B. P.: Pyroxene thermometry of rhyolite lavas of the Bruneau-Jarbidge eruptive center, Central Snake River Plain, J. Volcanol. Geotherm. Res., 188, 173-185, doi:10.1016/j.jvolgeores.2009.05.024, 2009. 
Chevrel, M. O., Cimarelli, C., deBiasi, L., Hanson, J., Lavallée, Y., Arzilli, F., and Dingwell, D. B.: Viscosity measurements of crystallizing andesite from Tungurahua volcano (Ecuador), Geochem. Geophys. Geosyst., 16, 870-889, doi:10.1002/2014GC005661, 2015.

Clift, R., Grace, J., and Weber, M. E.: Bubbles, Drops, and Particles, Dover Pubn Inc., 381 pp., 2005.

Coombs, M. L., Eichelberger, J. C., and Rutherford, M. J.: Experimental and textural constraints on mafic enclave formation in volcanic rocks, J. Volcanol. Geoth. Res., 119, 125-144, 2003.

De Campos, C. P., Dingwell, D. B., Perugini, D., Civetta, L., and Fehr, T. K.: Heterogeneities in magma chambers: Insights from the behavior of major and minor elements during mixing experiments with natural alkaline melts, Chem. Geol., 256, 131-145, 2008.

De Campos, C. P., Ertel-Ingrisch, W., Perugini, D., Dingwell, D. B., and Poli, G.: Chaotic mixing in the system earth: mixing granitic and basaltic liquids, in: Chaotic Systems: Theory and Application, edited by: Skiadas, C. H. and Dimotilakis, I., Int. Publ. Com., 51-58, 2010.

De Campos, C., Perugini, D., Ertel-Ingrisch, W., Dingwell, D., and Poli, G.: Enhancement of magma mixing efficiency by chaotic dynamics: an experimental study, Contrib. Mineral. Petr., 161, 863-881, doi:10.1007/s00410-010-0569-0, 2011.

Dingwell, D. B.: Viscosity-temperature relationships in the system $\mathrm{Na}_{2} \mathrm{Si}_{2} \mathrm{O}_{5}-\mathrm{Na}_{4} \mathrm{Al}_{2} \mathrm{O}_{5}$, Geochim. Cosmochim. Ac., 50, 12611265, doi:10.1016/0016-7037(86)90409-6, 1986.

Dingwell, D. B.: Effects of structural relaxation on cationic tracer diffusion in silicate melts, Chem. Geol., 82, 209-216, doi:10.1016/0009-2541(90)90082-i, 1990.

Eichelberger, J. C.: Vesiculation of mafic magma during replenishment of silicic magma reservoirs, Nature, 288, 446-450, 1980.

Giordano, D., Russell, J. K., and Dingwell, D. B.: Viscosity of magmatic liquids: a model, Earth Planet. Sc. Lett., 271, 123-134, 2008.

Helo, C., Longpre, M.-A., Shimizu, N., Clague, D. A., and Stix, J.: Explosive eruptions at mid-ocean ridges driven by $\mathrm{CO}_{2}$-rich magmas, Nature Geosci, advance online publication, available at: http://www.nature.com/ngeo/journal/vaop/ncurrent/abs/ ngeo1104.html\#supplementary-information, 2011.

Huppert, H. E. and Turner, J. S.: Double-diffusive convection, J. Fluid Mech., 106, 299-329, doi:10.1017/S0022112081001614, 1981.

Huppert, H. E., Sparks, R. S. J., and Turner, J. S.: Laboratory investigations of viscous effects in replenished magma chambers, Earth Planet. Sc. Lett., 65, 377-381, 1983.

Huppert, H. E., Stephen, R., Sparks, J., and Turner, J. S.: Some effects of viscosity on the dynamics of replenished magma chambers, J. Geophys. Res., 89, 6857-6877, doi:10.1029/JB089iB08p06857, 1984.

Izbekov, P. E., Eichelberger, J. C., and Ivanov, B. V.: The 1996 eruption of Karymsky Volcano, Kamchatka: historical record of basaltic replenishment of an andesite reservoir, J. Petrol., 45, 2325-2345, 2004.

Jochum, K. P., Dingwell, D. B., Rocholl, A., Stoll, B., Hofmann, A. W., Becker, S., Besmehn, A., Bessette, D., Dietze, H. J., Dulski, P., Erzinger, J., Hellebrand, E., Hoppe, P., Horn, I., Janssens, K., Jenner, G. A., Klein, M., McDonough, W. F., Maetz, M., Mezger, K., Munker, C., Nikogosian, I. K., Pick- hardt, C., Raczek, I., Rhede, D., Seufert, H. M., Simakin, S. G., Sobolev, A. V., Spettel, B., Straub, S., Vincze, L., Wallianos, A., Weckwerth, G., Weyer, S., Wolf, D., and Zimmer, M.: The preparation and preliminary characterisation of eight geological MPI-DING reference glasses for in-site microanalysis, Geostandard. Newslett., 24, 87-133, doi:10.1111/j.1751908X.2000.tb00590.x, 2000.

Kojima, M., Hinch, E. J., and Acrivos, A.: The formation and expansion of a toroidal drop moving in viscous fluid, Phys. Fluids, 27, 19-32, 1984.

Lacaze, L., Guenoun, P., Beysens, D., Delsanti, M., Petitjeans, P., and Kurowski, P.: Transient surface tension in miscible liquids, Phys. Rev. E, 82, 041606, doi:10.1103/PhysRevE.82.041606, 2010.

Lohmar, S., Parada, M., Gutiérrez, F., Robin, C., and Gerbe, M. C.: Mineralogical and numerical approaches to establish the preeruptive conditions of the mafic Licán Ignimbrite, Villarrica Volcano (Chilean Southern Andes), J. Volcanol. Geoth. Res., 235236, 55-69, doi:10.1016/j.jvolgeores.2012.05.006, 2012.

Manga, M. and Stone, H. A.: Low Reynolds number motion of bubbles, drops and rigid spheres through fluid-fluid interfaces, J. Fluid Mech., 287, 279-298, doi:10.1017/S0022112095000954, 1995.

Morgavi, D., Perugini, D., De Campos, C. P., Ertel-Ingrisch, W., and Dingwell, D. B.: Morphochemistry of patterns produced by mixing of rhyolitic and basaltic melts, J. Volcanol. Geoth. Res., 253, 87-96, doi:10.1016/j.jvolgeores.2012.12.007, 2013a.

Morgavi, D., Perugini, D., De Campos, C. P., Ertl-Ingrisch, W., Lavallée, Y., Morgan, L., and Dingwell, D. B.: Interactions between rhyolitic and basaltic melts unraveled by chaotic mixing experiments, Chem. Geol., 346, 199-212, doi:10.1016/j.chemgeo.2012.10.003, 2013b.

Morgavi, D., Perugini, D., De Campos, C. P., Ertel-Ingrisch, W., and Dingwell, D. B.: Time evolution of chemical exchanges during mixing of rhyolitic and basaltic melts, Contrib. Mineral. Petr., 166, 615-638, doi:10.1007/s00410-013-0894-1, $2013 \mathrm{c}$.

Mungall, J. E.: Interfacial Tension in Miscible Two-Fluid Systems with Linear Viscoelastic Rheology, Phys. Rev. Lett., 73, 288291, 1994.

Pallister, J. S., Hoblitt, R. P., and Reyes, A. G.: A basalt trigger for the 1991 eruptions of Pinatubo volcano?, Nature, 356, 426-428, 1992.

Perugini, D. and Poli, G.: Chaotic dynamics and fractals in magmatic interaction processes: a different approach to the interpretation of mafic microgranular enclaves, Earth Planet. Sc. Lett., 175, 93-103, doi:10.1016/S0012-821X(99)00282-4, 2000.

Perugini, D. and Poli, G.: Analysis and numerical simulation of chaotic advection and chemical diffusion during magma mixing: petrological implications, Lithos, 78, 43-66, 2004.

Perugini, D., Poli, G., and Gatta, G. D.: Analysis and simulation of magma mixing processes in 3D, Lithos, 65, 313-330, 2002.

Perugini, D., Poli, G., and Mazzuoli, R.: Chaotic advection, fractals and diffusion during mixing of magmas: evidence from lava flows, J. Volcanol. Geoth. Res., 124, 255-279, 2003.

Perugini, D., Petrelli, M., and Poli, G.: Diffusive fractionation of trace elements by chaotic mixing of magmas, Earth Planet. Sc. Lett., 243, 669-680, 2006. 
Perugini, D., De Campos, C. P., Dingwell, D. B., Petrelli, M., and Poli, G.: Trace element mobility during magma mixing: Preliminary experimental results, Chem. Geol., 256, 146-157, 2008.

Perugini, D., De Campos, C. P., Ertel-Ingrisch, W., and Dingwell, D. B.: The space and time complexity of chaotic mixing of silicate melts: implications for igneous petrology, Lithos, 155, 326-340, doi:10.1016/j.lithos.2012.09.010, 2012.

Perugini, D., De Campos, C. P., Dingwell, D. B., and Dorfman, A.: Relaxation of concentration variance: a new tool to measure chemical element mobility during mixing of magmas, Chem. Geol., 335, 8-23, doi:10.1016/j.chemgeo.2012.10.050, 2013.

Pouchou, J. L. and Pichoir, F.: Possibilités d'analyse en profondeur à la microsonde électronique, Microsc. Spectrosc. Electron., 9, 99-100, 1984.

Rallison, J. M.: The deformation of small viscous drops and bubbles in shear flows, Annu. Rev. Fluid Mech., 16, 45-46, 1984.

Ruprecht, P., Bergantz, G. W., and Dufek, J.: Modeling of gasdriven magmatic overturn: tracking of phenocryst dispersal and gathering during magma mixing, Geochem. Geophy. Geosy., 9, Q07017, doi:10.1029/2008GC002022, 2008.

Sánchez Mirón, A., Cerón García, M. C., García Camacho, F., Molina Grima, E., and Chisti, Y.: Mixing in bubble column and airlift reactors, Chem. Eng. Res. Des., 82, 1367-1374, doi:10.1205/cerd.82.10.1367.46742, 2004.

Scherrer, M.: Characterization of synthetic alkali-rich silicate melts by EPMA and viscometry, MSc, Department für Geound Umweltwissenschaften, Ludwig-Maximilians-Universität, München, München, Germany, 57 pp., 2012.
Snyder, D. and Tait, S.: Magma mixing by convective entrainment, Nature, 379, 529-531, 1996.

Tait, S. and Jaupart, C.: Compositional convection in viscous melts, Nature, 338, 571-574, 1989.

Thomas, N., Tait, S., and Koyaguchi, T.: Mixing of stratified liquids by the motion of gas bubbles: application to magma mixing, Earth Planet. Sci. Lett., 115, 161-175, doi:10.1016/0012821x(93)90220-4, 1993.

Wiesmaier, S., Deegan, F., Troll, V., Carracedo, J., Chadwick, J., and Chew, D.: Magma mixing in the 1100 AD Montaña Reventada composite lava flow, Tenerife, Canary Islands: interaction between rift zone and central volcano plumbing systems, Contrib. Mineral. Petr., 162, 651-669, doi:10.1007/s00410-0100596-x, 2011.

Wiesmaier, S., Troll, V. R., Carracedo, J. C., Ellam, R. M., Bindeman, I., and Wolff, J. A.: Bimodality of lavas in the TeidePico Viejo succession in Tenerife - the role of crustal melting in the origin of recent phonolites, J. Petrol., 53, 2465-2495, doi:10.1093/petrology/egs056, 2012.

Wilcox, R. E.: The idea of magma mixing: history of a struggle for acceptance, J. Geol., 107, 421-432, doi:10.1086/314357, 1999.

Woods, A. W. and Cowan, A.: Magma mixing triggered during volcanic eruptions, Earth Planet. Sci. Lett., 288, 132-137, doi:10.1016/j.epsl.2009.09.015, 2009.

Zhang, Y.: Diffusion in Minerals and Melts: theoretical Background, Rev. Mineral. Geochem., 72, 5-59, 2010. 